\title{
Stereotactic Radiosurgery and Stereotactic Radiotherapy for Malignant Skull Base Tumors
} Yoshimasa Mori
7

1. Radiation Oncology and Neurological Surgery, Shin-Yurigaoka General Hospital, Kawasaki, JPN 2. Radiology and Radiation Oncology, Aichi Medical University, Nagakute, JPN 3. Neurological Surgery, Ookuma Hospital, Nagoya, JPN 4. Neurological Surgery, Aoyama General Hospital, Toyokawa, JPN 5. Neurological Surgery, Gamma Knife Center, Ookuma Hospital, Nagoya, JPN 6. Cyberknife Center, Aoyama General Hospital, Toyokawa, JPN 7. CyberKnife Center, Aoyama General Hospital, Toyokawa, JPN

Corresponding author: Yoshimasa Mori, yoshimmori@yahoo.co.jp

\section{Abstract}

The role of stereotactic radiosurgery/stereotactic radiotherapy (SRS/SRT) for malignant skull base tumors was summarized and discussed. The treatment of skull base tumors remains challenging. Their total resection is often difficult. SRS/SRT is one useful treatment option for residual or recurrent tumors after surgical resection in cases of primary skull base tumors. If skull base metastasis and skull base invasion are relatively localized, they can be candidates for SRS/SRT. Low rates of cervical lymph node involvement in early-stage (NOM0, no lymph node involvement or distant metastasis) nasal and paranasal carcinomas (NpNCa) and external auditory canal carcinomas (EACCa) have been reported in the literature. Such cases might be good candidates for SRS/SRT as the initial therapy. We previously reported the results of SRS/SRT for various malignant extra-axial skull base tumors. In addition, treatment results of early-stage head and neck carcinomas were summarized. Those of our data and those of other reported series were reviewed here to clarify the usefulness of SRS/SRT for malignant extra-axial skull base tumors.

Received 03/15/2020

Review began 05/16/2020 Review ended 05/19/2020 Published 06/01/2020

\section{() Copyright 2020}

Mori et al. This is an open access article distributed under the terms of the Creative Commons Attribution License CC-BY 4.0., which permits unrestricted use, distribution, and reproduction in any medium, provided the original author and source are credited.

Categories: Pathology, Radiation Oncology, Neurosurgery

Keywords: tumor, skull base, stereotactic radiotherapy, radiosurgery, chordoma, paraganglioma, meningioma, hemangiopericytoma, external auditory canal, nasal

\section{Introduction And Background}

Treatment of skull base tumors is challenging. Their total resection is often difficult, as they involve or are located adjacent to various important structures including cranial nerves, major vessels, and the brainstem [1]. Stereotactic radiosurgery/stereotactic radiotherapy (SRS/SRT) is one treatment option for residual or recurrent tumors after surgical resection in cases of primary skull base tumors such as chordoma, paraganglioma, and non-benign meningioma [2]. If skull base metastasis and skull base invasion are relatively localized, they are good candidates of SRS/SRT.

We have hitherto reported the results of SRS/SRT for various malignant extra-axial skull base tumors [3-13]. They were summarized with additional data on SRS/SRT of skull-base involvement of head and neck carcinomas. The role of SRS/SRT for skull base malignant tumors was summarized and discussed.

\section{Review}

Various kinds of malignant tumors arise in the skull base (Table 1). 


\section{Cureus}

Skull base tumors

i) Primary tumors

Chordoma/Chondrosarcoma, Paraganglioma, Meningioma (atypical/malignant), Hemangiopericytoma (Solitary fibrous tumor)

ii) Skull base cancers

a) Metastasis and invasion to the skull base

Distant metastasis from visceral cancers, Direct invasion of head \& neck cancers

b) Early-stage head \& neck cancers

Orbital, nasal, \& paranasal cancers, External auditory canal cancers

\section{TABLE 1: Intracranial extra-axial malignant tumors including skull base tumors}

In primary tumors, SRS/SRT is a treatment option after surgical resection with histological diagnosis. Localized distant metastases to the skull base could be treated on the basis of clinical diagnosis. Skull base invasion of head and neck cancers, most commonly recurrent after 1st line treatment including radiation therapy, can be treated by SRS/SRT, if the lesion is relatively localized. Furthermore, of various head and neck cancers, low rates of cervical lymph node involvement in early-stage nasal and paranasal carcinomas (NpNCa) and external auditory canal carcinomas (EACCa) have been reported in the literature [14-16, 17,18]. This might make them good candidates for SRS/SRT, instead of surgical extirpation.

\section{Chordoma}

Chordoma has a clinically malignant nature invading skull base structures. Total resection is always difficult, and marginal recurrence often develops. In such cases, SRS/SRT can be expected to control the recurrent or residual tumor instead of repeat surgery.

Mori et al. reported the treatment results of Gamma Knife SRS (GK-SRS) for chordoma in seven patients (Table 2) [3-6]. Although the sample size was small, the follow-up period was relatively long. Five-year local control rates (LCRs) of treated tumors, residual and recurrent after surgical resection, were $67 \%$. With additional treatment for marginal and distant relapse, the five-year disease specific survival rate (DSSR) was 100\%. They used mainly SRS by Gamma Knife (GK) (Elekta, Tokyo). In addition, SRT using Novalis (BrainLAB, Tokyo) was done for recurrence in one case, as the recurrent tumors were relatively large and fractionated SRT was deemed better to avoid adverse radiation effects. They delivered a single marginal dose of 15 to $20 \mathrm{~Gy}$ (median, $16 \mathrm{~Gy}$ ) to the target tumors of 0.6 to $24 \mathrm{ml}$ in volume. Temporary adverse effects were limited to only a single case in which right trigeminal nerve deficits, hypesthesia in the right cheek and right masseter muscle weakness were reported. 


\section{Cureus}

\begin{tabular}{|c|c|c|c|c|c|c|}
\hline Diagnosis & Author, Year & Modality & $\begin{array}{l}\text { No. of pts. } \\
\text { (No. of } \\
\text { lesions) }\end{array}$ & Loca control & Survival & Additional Tx \\
\hline Chordoma & $\begin{array}{l}\text { Mori et al., } \\
2014[3]\end{array}$ & GK-SRS & $7(7)$ & $\begin{array}{l}86 \%(3 \mathrm{yr}) 67 \%(5 \\
\mathrm{yr})\end{array}$ & $\begin{array}{l}86 \% \text { \%*夫 (FU, } \\
68-175 \text { mos.) }\end{array}$ & $\begin{array}{l}\text { Repeat GK-SRS in four, Novalis } \\
\text { SRT in one, Resection in one }\end{array}$ \\
\hline $\begin{array}{l}\text { Paraganglioma (Glomus } \\
\text { tumor) }\end{array}$ & $\begin{array}{l}\text { Kida et al., } \\
2000[4]\end{array}$ & GK-SRS & $4(5)$ & $100 \%$ & $\begin{array}{l}100 \% \text { (FU, } \\
24-72 \text { mos.) }\end{array}$ & None \\
\hline $\begin{array}{l}\text { Non-benign meningioma } \\
\text { (atypical / malignant) }\end{array}$ & $\begin{array}{l}\text { Mori et al., } \\
2013[5]\end{array}$ & GK-SRS & $23(26)$ & $\begin{array}{l}74 \%(1 \mathrm{yr}) 52 \%(2 \\
\mathrm{yr}) 32 \%(3 \mathrm{yr})^{\star}\end{array}$ & 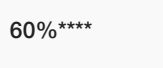 & $\begin{array}{l}\text { Repeat GK-SRS in four, Resection } \\
\text { in six }\end{array}$ \\
\hline $\begin{array}{l}\text { Hemangiopericytoma } \\
\text { (solitary fibrous tumor) }\end{array}$ & $\begin{array}{l}\text { Tsugawa et } \\
\text { al., } 2014 \text { [6] }\end{array}$ & GK-SRS & $7(10)$ & $\begin{array}{l}100 \%(1 \mathrm{yr}) 92 \%(2 \\
\mathrm{yr}) 70 \%(3 \mathrm{yr})^{\star \star}\end{array}$ & 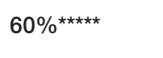 & Repeat GK-SRS in three \\
\hline
\end{tabular}

\section{TABLE 2: Our published results of stereotactic radiosurgery for chordoma and paraganglioma}

*Relapse (local or distant) occurred in $13(57 \%)$

${ }^{*}$ Relapse (local or distant) occurred in $4(57 \%)$

*** One patient died of intracranial dissemination of the tumor at 87 mos. after SRS

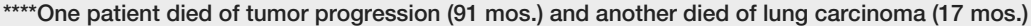

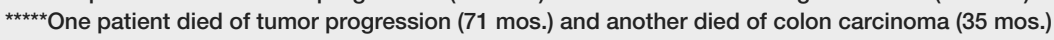

No. = number; pts. = patients; GK = Gamma Knife; SRS = Stereotactic radiosurgery; SRT = Stereotactic radiotherapy; yr = year; mos. = months; FU = Follow-up; LCR = Local control rate; Tx = Therapy.

A number of papers have been published on chordoma SRS/SRT both with particle-beam and photon-beam [3, 19-23, 24-28]. However, in early-reported series the treatment results of both chordoma and chondrosarcoma were mixed [29]. Reported series dealing with only chordoma were summarized in Table 3 for particle-beams and in Table 4 for photon-beams [3, 19-23, 24-28]. Relatively larger volume cases were treated effectively by particle beam series with a more frequent fraction schedule.

\begin{tabular}{|c|c|c|c|c|c|c|c|}
\hline Author, Year & Modality & $\begin{array}{l}\text { No. of } \\
\text { Pts. }\end{array}$ & Median Vol. (ml) & Median Dose (Gy) & $\begin{array}{l}\text { Local } \\
\text { Control (\%) }\end{array}$ & Survival (\%) & $\begin{array}{l}\text { Side } \\
\text { Effects }\end{array}$ \\
\hline Igakı et al., 2004 [19] & $\mathrm{P}$ & 13 & $27.4(3.3-88.4)$ & $\begin{array}{l}73.5 \text { Gy / } 33 \text { fx. }(64.0-103.1 / 20- \\
38 \text { fx.) })^{*}\end{array}$ & 46 (5 yr) & $\begin{array}{l}84.6(3 \mathrm{yr}), 63.6 \\
(5 \mathrm{yr})\end{array}$ & $15 \%$ \\
\hline $\begin{array}{l}\text { Schulz-Ertner et al., } \\
2007 \text { [20] }\end{array}$ & $\mathrm{C}$ & 96 & $\begin{array}{l}80.3(\mathrm{PTV}[2 \mathrm{~mm}]) \\
(13.9-594.2)\end{array}$ & 60 CGE / 20 tx. (60-70) & $\begin{array}{l}80.6(3 \mathrm{yr}), 70 \\
(5 \mathrm{yr})\end{array}$ & $\begin{array}{l}91.8(3 \mathrm{yr}), 88.5 \\
(5 \mathrm{yr})\end{array}$ & $6 \%$ \\
\hline Mizoe, 2016 [21] & $\mathrm{C}$ & 33 & $32(2-328)$ & 60.8 GyE / 16 fx. (48.0-60.8) & 85 (5 yr) & $88(5 \mathrm{yr})$ & $3 \%$ \\
\hline Uhl et al., 2014 [22] & $\mathrm{C}$ & 155 & $70(2-294)$ & 60 Gy (RBE) / 20 fx. (14-15) & $\begin{array}{l}82(3 \mathrm{yr}), 72 \\
(5 \mathrm{yr})\end{array}$ & $\begin{array}{l}95(3 \mathrm{yr}), 85(5 \\
\mathrm{yr})\end{array}$ & $\begin{array}{l}\text { (not } \\
\text { much) }\end{array}$ \\
\hline $\begin{array}{l}\text { Takagi et al., } 2018 \\
\text { [23] }\end{array}$ & Por & $\begin{array}{l}24 \\
(13+11)\end{array}$ & $17(0.4-131.1)$ & $\begin{array}{l}65.0 \text { Gy (RBE) / } 26 \text { fx. (57.6- } \\
74.0 / 16-37 \text { fx.) }\end{array}$ & 85 (5 yr) & 86 (5 yr) & $50 \%$ \\
\hline
\end{tabular}

\section{TABLE 3: Reported results of particle beam radiation therapy for skull base chordoma}

*equivalent dose calculated with alpha/beta of 7

Pts. = patients; Vol. = volume; $y r=$ year; $f x .=$ fraction; $P=$ proton; $C=$ carbon; $P T V=$ planning target volume; CGE = cobalt gray equivalent; $R B E=$ relative biological effectiveness. 


\section{Cureus}

\begin{tabular}{|c|c|c|c|c|c|c|c|}
\hline Author, Year & Modality & $\begin{array}{l}\text { No. of } \\
\text { Pts. }\end{array}$ & Median Vol. (ml) & Mean Margin Dose (Gy) & $\begin{array}{l}\text { Local Control } \\
\text { (\%) }\end{array}$ & Survival (\%) & $\begin{array}{l}\text { Side } \\
\text { Effects }\end{array}$ \\
\hline Liu et al., 2008 [24] & GK & 31 & $\begin{array}{l}11.4 \text { (mean) } \\
(0.47-27.6)\end{array}$ & 12.7 SRS (10-16) & $\begin{array}{l}64.2(3 \mathrm{yr}), 21.4 \\
(5 \mathrm{yr})\end{array}$ & $\begin{array}{l}90.9(3 \mathrm{yr}), 75.8 \\
(5 \mathrm{yr})\end{array}$ & none \\
\hline $\begin{array}{l}\text { Kano et al., } 2011 \\
\text { [25] }\end{array}$ & GK & 71 & $7.1(0.9-109)$ & 15.0 SRS (9-25) & $66(5 \mathrm{yr})$ & $\begin{array}{l}93.4(3 \mathrm{yr}), 80.2 \\
(5 \mathrm{yr})\end{array}$ & $9 \%$ \\
\hline $\begin{array}{l}\text { Hafez et al., } 2019 \\
\text { [26] }\end{array}$ & GK & 12 & 7.0 (mean) & 14.3 SRS & $\begin{array}{l}30(3 \mathrm{yr}), 25(5 \\
y r)\end{array}$ & $\begin{array}{l}\text { FU (12-120 } \\
\text { mos.) }\end{array}$ & none \\
\hline $\begin{array}{l}\text { Mori et al. (ours), } \\
2014 \text { [3] }\end{array}$ & GK & 7 & $5.1(0.6-11.4)$ & 16.9 SRS (15-20) & $\begin{array}{l}86(3 \mathrm{yr}), 67(5 \\
y r)\end{array}$ & $\begin{array}{l}100(5 \mathrm{yr}), 50(10 \\
\mathrm{yr})\end{array}$ & $(14 \%)^{\star}$ \\
\hline $\begin{array}{l}\text { Zorlu et al., } 2014 \\
\text { [27] }\end{array}$ & CK & 11 & $14.7(3.9-40.5)$ & 30/5 fx. (median) (30-36/3-5 fx.) & $\begin{array}{l}80(3 \mathrm{yr}), 25(5 \\
y r)\end{array}$ & $91(2 \mathrm{yr})$ & $18 \%$ \\
\hline $\begin{array}{l}\text { Bugoci et al., } 2013 \\
\text { [28] }\end{array}$ & LINAC & 12 & $19.5(8.5-73.2)$ & $\begin{array}{l}\text { 66.6/37 fx. (median) (48.6- } \\
68.4 / 27-38 \text { fx.) }\end{array}$ & $\begin{array}{l}46.9(2 \mathrm{yr}), 37.5 \\
(5 \mathrm{yr})\end{array}$ & 76.4 (5 yr) & ND \\
\hline
\end{tabular}

\section{TABLE 4: Reported results of photon beam radiotherapy for chordoma}

*Only temporary adverse effects

Pts. = patients; Vol. = volume; yr = year; GK = Gamma Knife; CK = CyberKnife; LINAC = linear accelerator-based system; SRS = stereotactic radiosurgery; ND = not described.

Photon beam seemed to be effective if the target tumors were not large and when large a single fraction dose was used.

After surgery or SRS/SRT timely assessment in cases developing local or marginal relapse with repeat SRS/SRT or surgical resection is indispensable to control chordoma, which shows a proclivity to develop repeat recurrence.

SRS/SRT is effective also in skull base chondrosarcoma residual and recurrent after surgical resection [30]. The prognosis was reported to be a little better for chondrosarcoma [31]. Murakami et al. reported a case of skull base mesenchymal chondrosarcoma, surviving more than 10 years after the initial surgery, with repeated SRS/SRT in addition to surgical resection 10 times [32]. They concluded that the extent of the initial resection is important for treatment outcome.

\section{Paraganglioma (Glomus tumor)}

Paraganglioma located at the skull base is also difficult to manage. Paraganglioma often arises around the jugular bulb system and involves cranial nerves such as the lower cranial nerves. It often exists over intracranial and infracranial spaces in a dumbbell shape. In addition, it is vascular-rich. Total resection of the tumor is often difficult.

Kida et al. reported the treatment results of GK-SRS for paraganglioma in four cases (five tumors) (Table 2) [4]. Five-year LCR of treated tumors residual and recurrent after surgical resection was $100 \%$. They delivered a mean margin dose of $15.5 \mathrm{~Gy}$ (range, 15.0-16.0) to targets of 23.3 to $36.1 \mathrm{~mm}$ (mean 28.4) in diameter.

Recent reported series are summarized in Table 5 [4, 33-37]. 


\section{Cureus}

\begin{tabular}{|c|c|c|c|c|c|c|c|}
\hline Author, Year & Modality & $\begin{array}{l}\text { No. of } \\
\text { Pts. }\end{array}$ & Median Vol. (ml) & Mean Margin Dose (Gy) & Local Control (\%) & Survival (\%) & $\begin{array}{l}\text { Side } \\
\text { Effects }\end{array}$ \\
\hline $\begin{array}{l}\text { Hafez et al., } 2016 \\
{[33]}\end{array}$ & GK & 22 & $\begin{array}{l}7.3 \text { (mean) (2.8- } \\
19.4)\end{array}$ & 14.7 SRS (12-16) & $\begin{array}{l}95.5 \text { (5 yr, PFS), } \\
95.5 \text { (7 yr) }\end{array}$ & $\begin{array}{l}95.5(5 \mathrm{yr}), 95.5 \\
(7 \mathrm{yr})\end{array}$ & ND \\
\hline $\begin{array}{l}\text { Dobberpuhl et al., } \\
2016 \text { [34] }\end{array}$ & GK & 12 & $\begin{array}{l}\text { up to } 4.5 \mathrm{~cm} \text { in } \\
\text { diameter }\end{array}$ & $(12-18)$ & 100 (FU, 13-96 mo) & $\begin{array}{l}100 \text { (FU, 13-96 } \\
\text { mo) }\end{array}$ & none \\
\hline $\begin{array}{l}\text { Winford et al., } 2017 \\
\text { [35] }\end{array}$ & GK & 33 & $\begin{array}{l}5.8 \text { (mean) }(0.9- \\
11.4)\end{array}$ & 13.2 SRS (11-15) & $\begin{array}{l}95 \text { (5 yr, PFS), } 75 \\
(10 \mathrm{yr})\end{array}$ & $\begin{array}{l}100 \text { (FU, 5.5- } \\
141 \mathrm{mo})\end{array}$ & $3.7 \%$ \\
\hline $\begin{array}{l}\text { Kida et al., (ours), } \\
2000 \text { [4] }\end{array}$ & GK & 4 & $11.6(7.5-23.5)$ & 15.5 SRS (15-16) & 100 (5 yr) & 100 (5 yr) & none \\
\hline $\begin{array}{l}\text { Tripathi et al., } 2019 \\
\text { [36] }\end{array}$ & $\begin{array}{l}\text { GK } \\
\text { SRS/SRT }\end{array}$ & 10 & $\begin{array}{l}29.9 \text { (mean) (9.95- } \\
47.6)\end{array}$ & $\begin{array}{l}\text { (16-22 SRS, } 22.4 / 2 \text { fx. or } \\
22.9 / 3 \text { fx.) }\end{array}$ & 100 (FU, 12-78 mo) & $\begin{array}{l}100 \text { (FU, 12-78 } \\
\mathrm{mo})\end{array}$ & $1.8 \%$ \\
\hline Gigliotti et al., 2018 & $\begin{array}{l}\text { LINAC } \\
\text { SRS/SRT }\end{array}$ & 16 & 11.7 (PTV) & $\begin{array}{l}\text { (15 SRS, } 21 / 3 \text { fx., or 25- } \\
27.5 / 5 \text { fx.) }\end{array}$ & 88 (5 yr) & $\begin{array}{l}100 \text { (FU, 55-87 } \\
\mathrm{mo})\end{array}$ & $6 \%$ \\
\hline
\end{tabular}

TABLE 5: Reported results of stereotactic radiosurgery/stereotactic radiotherapy for paraganglioma (Glomus tumor)

Pts. = patients; Vol. = volume; $y r=$ year; $\mathrm{mo}=$ months; GK = Gamma Knife; LINAC = linear accelerator-based system; SRS = stereotactic radiosurgery; $\mathrm{SRT}$ = stereotactic radiotherapy; $\mathrm{PFS}$ = progression-free survival; FU = follow-up.

Tripathi et al. used a hypofractionated schedule using GK [36]. Gigliotti et al. reported the results of Linacbased SRT [37]. Recently, we treated two cases of large recurrent paraganglioma by two-volume staged GKSRT (unpublished data).

\section{Non-benign meningioma}

Histologically $4-7 \%$ of meningiomas are considered atypical meningioma (AM) and $1-2 \%$ are malignant meningioma (MM) [5]. Non-benign meningiomas tend to recur within a relatively short term even after radical surgical resection.

Mori et al. reported the treatment results of GK-SRS for atypical and malignant meningioma in 23 cases (36 tumors) (Table 2) [5]. Three-year LCR in non-benign meningioma was 34\%. Three-year DSSR was $91 \%$. They delivered a mean marginal dose of $16.7 \mathrm{~Gy}$ (range 11.0 to 21.15 ) to the targets of 0.4 to $35.3 \mathrm{ml}$ (median 8.6) in volume. They concluded that regular neuroradiological follow-up with timely identification of the development of new tumors or progression of the treated neoplasm followed by repeat management of SRS/SRT or microsurgery is important for prolongation of patient survival.

Acker et al. reported the results of CyberKnife SRS/SRT for AM and MM in 35 patients (127 tumors) [38]. Single-fraction SRS in the range of 15-18 Gy, or SRT of 21-24 Gy in three fractions, or 20-25 Gy in 4-5 fractions was delivered. The LCRs were $97 \%, 77 \%$, and $67 \%$ at one, two, and five years, respectively, in AM and 66\% each at one and two years in MM. The regional progression-free survival (PFS) was 93\%, 73\%, and $59 \%$ at one, three, and five years, respectively, in AM and 93\% and 46\% at one and two years in MM. The estimated distant tumor PFS in AM was $80 \%, 44 \%$, and $44 \%$ at one, three, and five years, respectively, and $49 \%$ and $24 \%$ at one and two years, respectively, in MM. They treated the median planning target volume of $1.71 \mathrm{ml}$ (range, 0.06 to 22.5 ) mostly by single-session SRS.

Recently Wu et al. published a review of the results of particle radiotherapy for WHO grade II (AM) and grade III meningiomas (MM) in 11 articles including 240 patients [39]. LCR at five years or at the end of the followup (median 145 months) ranged from 46.7 to $86 \%$. Radiation necrosis was reported in 3.9\% (3/77 patients) across the three studies available. Of them only one patient, who had had previous radiotherapy to the pituitary region, showed serious radiation necrosis (Common Terminology Criteria for Adverse Events (CTCAE) Grade 3).

Kaur et al. also published a review article on adjuvant radiotherapy for AM and MM [40]. The median fiveyear PFS and overall survival (OS) were 54.2\% and 67.5\%, respectively, for AM and $48 \%$ and 55.6\% for MM. The complication rates were $11.1 \%$ for AM and 5.1\% for MM. They described that incomplete resection and radiation dose < 50 Gy conferred significantly poorer five-year PFS. Adjuvant radiotherapy improved local control especially in patients with subtotally resected AM and MM, while inducing modest treatment toxicity. However, in patients with completely excised AM adjuvant radiotherapy did not confer any 


\section{Hemangiopericytoma (Solitary fibrous tumor)}

The clinical behavior of hemangiopericytoma is more aggressive than that of meningioma. This tumor is notable not only for its local aggressiveness and high rate of recurrence but also for its proclivity to develop extracranial metastases [6]. Spina et al. published a systematic review of 18 studies including 208 patients (366 tumors) [41]. Radiotherapy modality was GK in 14 series and CyberKnife (CK) or linear acceleratorbased (LINAC) system in four. In the review of the literature, they described that the median time for recurrence was about five years, with PFSs of $96 \%, 49 \%$, and $28 \%$ at one, five, and 10 years, respectively. In addition, the incidence of metastasis increased over time, amounting to $13 \%, 33 \%$, and $64 \%$ at five, 10 , and 15 years, respectively.

Tsugawa et al. reported the treatment results of GK-SRS for hemangiopericytoma in seven cases (Table 2) [6]. LCR was $92 \%$ and $70 \%$ respectively at three and five years. Three-year and five-year DSSR were both $100 \%$. They gave a mean marginal dose of $16.5 \mathrm{~Gy}$ (range, 10 to 20 ) to the mean target volume of $4.1 \mathrm{ml}$ (range, 0.3 to 23.9). Cohen-Inbar et al. reported a multicenter study using GK [42]. Eight centers had treated a total of 90 patients harboring 133 tumors. A median margin dose of $15 \mathrm{~Gy}$ (range, 2.8-24) was delivered to a median tumor volume of $4.9 \mathrm{ml}$ (range, $0.2-42.4$ ). Crude LCR at the last follow-up was 55\% of tumors and $62.2 \%$ of patients. New remote intracranial tumors were noted in $27.8 \%$ of patients, and $24.4 \%$ of patients developed extracranial metastases. OS was $91.5 \%, 82.1 \%$, and $73.9 \%$, respectively at two years, four years, and six years. Local PFS was $81.7 \%, 66.3 \%$, and $54.5 \%$. They showed that the development of extracranial metastases influences OS, with PFS repeat (multiple) with SRS conferring additional benefit.

While hemangiopericytoma has a tendency to recur repeatedly, aggressive tumor management including repeat SRS/SRT or microsurgery for recurrent and newly developed tumors can prolong patient survival.

\section{Distant metastasis and direct invasion of malignancies}

Metastases to the skull base are challenging situations because they often involve critical structures including cranial nerves and induce progressive ipsilateral neurological deficits. Skull base infiltrations by direct invasion of a regional primary malignant tumor of head and neck cancers, for example along the cranial nerve routes, often occur. Both metastasis and invasion by carcinomas, when localized, can be treated effectively by SRS/SRT. A number of reported series have documented the effectiveness of SRS/SRT for both situations, which were mixed [43]. However, the respective results differed somewhat. Improvement of local cranial nerve impairment is more expected in cases of isolated distant metastases. Improvement of neurological symptoms was obtained in $91 \%(10 / 11)$ of cases of distant metastases in contrast to $40 \%(4 / 10)$ of direct skull base invasions by head and neck carcinomas (Table 6) [8,9]. Mori et al. delivered 30-50 Gy (mean 37.8) in 10-14 fractions to the planning target volume (PTV) of 8 to $112 \mathrm{ml}$ (mean 61.6).

\begin{tabular}{|c|c|c|c|c|c|c|}
\hline Diagnosis & Author, Year & Modality & $\begin{array}{l}\text { No. of } \\
\text { pts. }\end{array}$ & $\begin{array}{l}\text { Loca control } \\
\text { (crude) }\end{array}$ & Survival & Remark \\
\hline $\begin{array}{l}\text { Distant metastases from } \\
\text { visceral cancers }\end{array}$ & $\begin{array}{l}\text { Mori et al., } \\
2010[8]\end{array}$ & $\begin{array}{l}\text { Novalis- } \\
\text { SRT }\end{array}$ & 11 & $100 \%$ & $\begin{array}{l}36 \% \text { (FU, 5-36 } \\
\text { mos.) }\end{array}$ & Neurological improvement in 10 (91\%) \\
\hline $\begin{array}{l}\text { Direct invasion by head \& } \\
\text { neck cancers }\end{array}$ & Mori, 2011 [9] & $\begin{array}{l}\text { Novalis- } \\
\text { SRT }\end{array}$ & 15 & $69 \%$ & $\begin{array}{l}80 \% \text { (FU, 2-12 } \\
\text { mos.) }\end{array}$ & Neurological improvement in six $(40 \%)$ \\
\hline Nasal \& paranasal cancers & $\begin{array}{l}\text { Mori, 2005- } \\
2015 \text { [9-13] }\end{array}$ & $\begin{array}{l}\text { Novalis- } \\
\text { SRT }\end{array}$ & 4 & $100 \%$ & $\begin{array}{l}100 \% \text { (FU, 6-34 } \\
\text { mos.) }\end{array}$ & $\begin{array}{l}\text { SRT was performed as the initial } \\
\text { therapy for NOMO cases }\end{array}$ \\
\hline $\begin{array}{l}\text { External auditory canal } \\
\text { cancer }\end{array}$ & $\begin{array}{l}\text { (unpublished } \\
\text { data) }\end{array}$ & CK-SRT & 4 & $75 \%$ & $\begin{array}{l}100 \% \text { (FU, 24- } \\
72 \text { mos.) }\end{array}$ & $\begin{array}{l}\text { therapy for NOMO cases } \\
\text { the initial }\end{array}$ \\
\hline
\end{tabular}

TABLE 6: Our reported results of stereotactic radiotherapy for distant metastases, direct invasion by malignancies, and early-stage head and neck cancers (nasal and paranasal cancers and external auditory canal cancer

No. = number; pts. = patients; SRT = stereotactic radiotherapy; CK = CyberKnife; FU = follow-up; mos. = months; NOM0 = no lymph node involvement nor distant metastasis.

Minniti et al. also reported the effectiveness of SRT, good local control and neurological improvement, in cases of skull base metastases involving the anterior visual pathway [44]. They delivered $25 \mathrm{~Gy}$ in five fractions. In $51 \%$ of their patients clinical improvement of preexisting cranial nerve deficits was achieved. 


\section{Early-stage head \& neck cancers}

Of various head and neck cancers, it is reported that only $10-15 \%$ of early-stage nasal and paranasal carcinomas (NpNCa) have cervical lymph node (LN) involvement [14-16]. Also, patients with early-stage external auditory canal carcinomas (EACCa) rarely develop regional $\mathrm{LN}$ metastasis $[17,18]$. Such patients might be good candidates for SRS/SRT as an upfront therapy, instead of surgical extirpation, as the initial therapy. Crude control rates of early-stage NpNCa (four cases) and EACCa (four cases) after SRS/SRT were 100\% (6-34 months) and 75\% (19-166 months), respectively (Table 6) [9-13].

Indications and treatment planning, including optimal prescription dose, fraction schedule and field decision, will have to be established in future studies.

\section{SRS and SRT}

GK and cone collimated CK have similar dose distributions, steep dose fall-off around the target and relatively high doses inside the target. Gamma Knife procedures previously needed rigid head frame fixation with skull screws and were only suitable for single-session SRS. However, Icon (Elekta, Tokyo) with a relocatable thermoplastic facial mask system, good for fractionated SRT, has recently become available. We have used GK-SRS for relatively localized small tumors, especially postoperative residual and recurrent, in primary skull base tumors of chordoma, paraganglioma, meningioma, and hemangiopericytoma. If a relatively broad target with prophylactic surrounding area, i.e. the operative field of tumor bed, has to be included as the target, we have used Novalis or CK. Metastatic carcinomas with a highly invasive nature were targeted by LINAC, such as Novalis or TomoTherapy.

Considering chordoma, non-benign meningioma, and hemangiopericytoma, the feasibility of postoperative adjuvant therapy has to be established, even if the tumor is resected totally. The optimal treatment protocols for early-stage nasal and paranasal carcinomas and external ear canal carcinomas have to be established.

\section{Conclusions}

SRS/SRT has been clinically applied for various malignant skull base tumors successfully. However, further investigation of larger populations with longer follow-up periods will be necessary to establish optimal indications and treatment planning considering the histological diagnosis, location, and individual circumstances, including whether it is to be the initial radiotherapy or retreatment of the tumors.

\section{Appendices}

The authors have no financial or other conflicts of interest in relation to this research or its publication to declare.

The data on the EACCa patients were accumulated under the approval of the Ethical Committee Board of Shin-Yurigaoka General Hospital (20190520-2) and Aoyama General Hospital (19-02).

\section{Additional Information \\ Disclosures}

Conflicts of interest: In compliance with the ICMJE uniform disclosure form, all authors declare the following: Payment/services info: All authors have declared that no financial support was received from any organization for the submitted work. Financial relationships: All authors have declared that they have no financial relationships at present or within the previous three years with any organizations that might have an interest in the submitted work. Other relationships: All authors have declared that there are no other relationships or activities that could appear to have influenced the submitted work.

\section{References}

1. Mori Y, Nakazawa H, Hashizume C, Tsugawa T, Murai T: Dosimetric comparison of hypofractionated stereotactic radiotherapy by three different modalities for benign skull base tumors adjacent to functioning optic pathways. Int J Radiat Res. 2019, 17:519-530.

2. McCutcheon IE: Stereotactic radiosurgery for malignant extracerebral intracranial tumors: patient selection, efficacy, and technical nuances. Acta Neurochirurgica (Wien). 2013, 116:71-83. 10.1007/978-37091-1376-9_12

3. Mori Y, Kobayashi T, Tsugawa T, et al.: Gamma Knife stereotactic radiosurgery for postoperative residual and recurrent skull base chordoma. Stereotactic Radiotherapy (Tokyo). 2014, 18:169-175.

4. Kida Y, Kobayashi T, Mori Y: Gamma radiosurgery of glomus tumors . Neurosurg J (Tokyo). 2000, 9:603-609. 10.7887/jcns.9.603

5. Mori Y, Tsugawa T, Hashizume C, Kobayashi T, Shibamoto Y: Gamma knife stereotactic radiosurgery for atypical and malignant meningiomas. Acta Neurochir (Suppl). 2013, 116:85-89. 10.1007/978-3-7091-13769_13

6. Tsugawa T, Mori Y, Kobayashi T, Hashizume C, Shibamoto Y, Wakabayashi T: Gamma knife stereotactic 
radiosurgery for intracranial hemangiopericytoma. J Radiosurg SBRT. 2014, 3:29-35.

7. Mori Y, Kobayashi T, Shibamoto Y: Stereotactic radiosurgery for metastatic tumors in the pituitary gland and the cavernous sinus. J Neurosurg (Suppl). 2006, 105:37-42. 10.3171/sup.2006.105.7.37

8. Mori Y, Hashizume C, Kobayashi T, Shibamoto Y, Kosaki K, Nagai A: Stereotactic radiotherapy using Novalis for skull base metastases developing with cranial nerve symptoms. J Neurooncol. 2010, 98:213-219. 10.1007/s11060-010-0179-8

9. Mori Y: Skull-base malignant tumors. In: Shaped Beam Radiosurgery. De Salles AAF (ed): Springer-Verlag, Berlin, Heidelberg; 2011. 181-191. 10.1007/978-3-642-11151-8_16

10. Mori Y, Kobayashi T, Kida Y, Oda K, Shibamoto Y, Yoshida J: Stereotactic radiosurgery as a salvage treatment for recurrent skull base adenoid cystic carcinoma. Stereotact Funct Neurosurg. 2005, 83:202-207. $10.1159 / 000091084$

11. Oda K, Mori Y, Kobayashi T, Kida Y, Yokoi H, Shibamoto Y, Yoshida J: Stereotactic radiosurgery as a salvage treatment for recurrent epipharyngeal carcinoma. Stereotact Funct Neurosurg. 2006, 84:103-108. $10.1159 / 000094461$

12. Mori Y, Hashizume C, Tsugawa T, Kobayashi T, Shibamoto Y: Stereotactic radiotherapy (SRT) for recurrent olfactory neuroblastoma. Jpn J Clin Radiol (Tokyo). 2015, 60:675-679.

13. Mori Y: Nasal and paranasal malignant tumors. Clinical Aspects of Gamma Knife. Kida Y (ed): Medica Publishing, Tokyo; 2008. 224:78-74.

14. Cantù G, Bimbi G, Miceli R, et al.: Lymph node metastases in malignant tumors of the paranasal sinuses: prognostic value and treatment. Arch Otolaryngol Head Neck Surg. 2008, 134:170-177. 10.1001/archoto.2007.30

15. Pezner RD, Moss WT, Tong D, Blasko JC, Griffin TW: Cervical lymph node metastases in patients with squamous cell carcinoma of the maxillary antrum: the role of elective irradiation of the clinically negative neck. Int J Radiat Oncol Biol Phys. 1979, 5:1977-1980. 10.1016/0360-3016(79)90948-9

16. Kondo $\mathrm{M}$, Ogawa $\mathrm{K}$, Inuyama $\mathrm{Y}$, et al.: Prognostic factors influencing relapse of squamous cell carcinoma of the maxillary sinus. Cancer. 1985, 55:190-196. 10.1002/1097-0142(19850101)55:1<190::aidcncr2820550130>3.0.co;2-2

17. Shinomiya H, Uehara N, Teshima M, Kakigi A, Otsuki N, Nibu KI: Clinical management for T1 and T2 external auditory canal cancer. Auris Nasus Larynx. 2019, 46:785-789. 10.1016/j.anl.2019.02.004

18. Yoon M, Chougule P, Dufresne R, Wanebo HJ: Localized carcinoma of the external ear is an unrecognized aggressive disease with a high propensity for local regional recurrence. Am J Surg. 1992, 164:574-577. 10.1016/s0002-9610(05)80709-3

19. Igaki H, Tokuuye $\mathrm{K}$, Okumura $\mathrm{T}$, et al.: Clinical results of proton beam therapy for skull base chordoma . Int $\mathrm{J}$ Radiat Oncol Biol Phys. 2004, 60:1120-1126. 10.1016/j.ijrobp.2004.05.064

20. Schulz-Ertner D, Karger CP, Feuerhake A, et al.: Effectiveness of carbon ion radiotherapy in the treatment of skull-base chordomas. Int J Radiat Oncol Biol Phys. 2007, 68:449-457. 10.1016/j.ijrobp.2006.12.059

21. Mizoe JE: Review of carbon ion radiotherapy for skull base tumors (especially chordomas) . Rep Pract Oncol Radiother. 2016, 21:356-360.

22. Uhl M, Mattke M, Welzel T, et al.: Highly effective treatment of skull base chordoma with carbon ion irradiation using a raster scan technique in 155 patients: first long-term results. Cancer. 2014, 120:34103417. 10.1002/cncr.28877

23. Takagi M, Demizu Y, Nagano F, et al.: Treatment outcomes of proton or carbon ion therapy for skull base chordoma: a retrospective study. Radiat Oncol. 2018, 13:232. 10.1186/s13014-018-1173-0

24. Liu AL, Wang ZC, Sun SB, Wang MH, Luo B, Liu P: Gamma knife radiosurgery for residual skull base chordomas. Neurol Res. 2008, 30:557-561. 10.1179/174313208X297878

25. Kano H, Iqbal FO, Sheehan J, et al.: Stereotactic radiosurgery for chordoma: a report from the North American Gamma Knife Consortium. Neurosurgery. 2011, 68:379-389. 10.1227/NEU.0b013e3181ffa12c

26. Hafez RFA, Fahmy OM, Hassan HT: Gamma knife surgery efficacy in controlling postoperative residual clival chordoma growth. Clin Neurol Neurosurg. 2019, 178:51-55. 10.1016/j.clineuro.2019.01.017

27. Zorlu F, Gultekin M, Cengiz M, Yildiz F, Akyol F, Gurkaynak M, Ozyigit G: Fractionated stereotactic radiosurgery treatment results for skull base chordomas. Technol Cancer Res Treat. 2014, 13:11-19. 10.7785/tcrt.2012.500354

28. Bugoci DM, Girvigian MR, Chen JC, Miller MM, Rahimian J: Photon-based fractionated stereotactic radiotherapy for postoperative treatment of skull base chordomas. Am J Clin Oncol. 2013, 36:404-410. 10.1097/COC.0b013e318248dc6f

29. Hasegawa T, Ishii D, Kida Y, Yoshimoto M, Koike J, Iizuka H: Gamma Knife surgery for skull base chordomas and chondrosarcomas. J Neurosurg. 2007, 107:752-757. 10.3171/NNS-07/10/0752

30. Kano H, Sheehan J, Sneed PK, et al.: Skull base chondrosarcoma radiosurgery: report of the North American Gamma Knife Consortium. J Neurosurg. 2015, 123:1268-1275. 10.3171/2014.12.JNS132580

31. Kano H, Lunsford LD: Stereotactic radiosurgery of intracranial chordomas, chondrosarcomas, and Glomus tumors. Neurosurg Clin N Am. 2013, 24:533-560. 10.1016/j.nec.2013.05.009

32. Murakami Y, Jinguji S, Kishida Y, et al.: Multiple surgical treatments for repeated recurrence of skull base mesenchymal chondrosarcoma. NMC Case Rep J. 2018, 5:99-103. 10.2176/nmccrj.cr.2018-0016

33. Hafez RF, Morgan MS, Fahmy OM: An intermediate term benefits and complications of gamma knife surgery in management of glomus jugulare tumor. World J Surg Oncol. 2016, 14:36. 10.1186/s12957-016-0779-7

34. Dobberpuhl MR, Maxwell S, Feddock J, St Clair W, Bush ML: Treatment outcomes for single modality management of glomus jugulare tumors with stereotactic radiosurgery. Otol Neurotol. 2016, 37:1406-1410. 10.1097/MAO.0000000000001160

35. Winford TW, Dorton LH, Browne JD, Chan MD, Tatter SB, Oliver ER: Stereotactic radiosurgical treatment of glomus jugulare tumors. Otol Neurotol. 2017, 38:555-562. 10.1097/MAO.0000000000001336

36. Tripathi M, Rekhapalli R, Batish A, et al.: Safety and efficacy of primary multisession dose fractionated Gamma Knife radiosurgery for jugular paragangliomas. World Neurosurg. 2019, 131:136-148. 10.1016/i.wneu.2019.07.090

37. Gigliotti MJ, Hasan S, Liang Y, Chen D, Fuhrer R, Wegner RE: A 10-year experience of linear accelerator- 


\section{Cureus}

based stereotactic radiosurgery/radiotherapy (SRS/SRT) for paraganglioma: a single institution experience and review of the literature. J Radiosurg SBRT. 2018, 5:183-190.

38. Acker G, Meinert F, Conti A, et al.: Image-guided robotic radiosurgery for treatment of recurrent grade II and III meningiomas. A single-center study. World Neurosurg. 2019, 131:96-107.

10.1016/j.wneu.2019.07.058

39. Wu A, Jin MC, Meola A, Wong HN, Chang SD: Efficacy and toxicity of particle radiotherapy in WHO grade II and grade III meningiomas: a systematic review. Neurosurg Focus. 2019, 46:12. 10.3171/2019.3.FOCUS1967

40. Kaur G, Sayegh ET, Larson A, et al.: Adjuvant radiotherapy for atypical and malignant meningiomas: a systematic review. Neuro Oncol. 2014, 16:628-636. 10.1093/neuonc/nou025

41. Spina A, Boari N, Gagliardi F, Donofrio CA, Franzin A, Mortini P: The current role of Gamma Knife radiosurgery in the management of intracranial haemangiopericytoma. Acta Neurochir (Wien). 2016, 158:635-642. 10.1007/s00701-016-2742-3

42. Cohen-Inbar O, Lee CC, Mousavi SH, et al.: Stereotactic radiosurgery for intracranial hemangiopericytomas: a multicenter study. J Neurosurg. 2017, 126:744-754. 10.3171/2016.1.JNS152860

43. Iwai Y, Yamanaka K: Gamma Knife radiosurgery for skull base metastasis and invasion . Stereotact Funct Neurosurg. 1999, 72:81-87. 10.1159/000056443

44. Minniti G, Esposito V, Clarke E, et al.: Fractionated stereotactic radiosurgery for patients with skull base metastases from systemic cancer involving the anterior visual pathway. Radiat Oncol. 2014, 9:110. 10.1186/1748-717X-9-110 